\title{
REDESIGNING A NEGATIVE SPACE THROUGH CPTED IN SUSUKINO DISTRICT, SAPPORO, JAPAN
}

\author{
Sylviana Putri Sunario Soegondo \\ Department of Architecture, Petra Christian University \\ Jl. Siwalankerto 121-131, Surabaya, INDONESIA \\ Email: sylviana@petra.ac.id
}

\begin{abstract}
As an impact of prostitution site, criminality is triggered by a negative space; however, prostitution site in Japan is a part of the city. Susukino in Sapporo, for example, plays a role as a tourist attraction as well as a prostitution site. This research aims to figure out how the architectural design in Susukino influences criminality prevention as an effect of prostitution sites. Survey and interview were conducted to observe zonation in Susukino and to define a negative space as a problem of the district. Later, six aspects: 1) Defensible space, 2) Territoriality, 3) Surveillance, 4) Lighting, 5) Landscaping, and 6) Physical security; based on CPTED (Crime Prevention Through Environment Design) theory were applied as a basis to improve the quality of the street in the negative space by purifying the landmark and activating the street by adding positive functions.
\end{abstract}

Keywords: Negative Space; prostitution; tourism; CPTED.

\section{INTRODUCTION}

Different from other eastern cultures, prostitution in Japan is legally allowed, and it is accustomed to tourism. Susukino in Sapporo is one of the examples. As one of the biggest red-light districts in the most northern of Japan, Brothels at Susukino are counted as the supporting services for sexual demand during the post-war recession (Bloomberg, 2013). Showing by the survey conducted by BOJ (Bank of Japan), From 63 stores, the number of brothels rose to 264 , while the number of restaurants in the district declined by $14 \%$ between 1989 and 2008 (Bloomberg, 2013). This makes Susukino become an interesting place as an entertainment district both locally and globally. This district is not only satisfying the users but also bolstering up the economy as a tourism site. Besides, the existence of prostitution in the district brings a dilemma because it attracts gangsters then ended with criminality.

Through site observation, interviewing the inhabitants, identifying the land use, and categorizing the area; this research aim is to figure out the problem of the district and the solution on how the architectural design in Susukino prevent criminality based on Crime Prevention Through Environmental Design (CPTED).

\section{THEORETICAL FOUNDATION}

In accordance with the term, CPTED is managing safety through designing the environment. Proper design and effective use of the built environment are required to reduce the incidence and concern of crime (Lim, Tow Fok, 2003). Indeed, this successively results in enhancements within the quality of life (Lim, 2003).

To get it completely how CPTED is utilized, one must look at its components and the reasoning behind them. Although wrongdoing avoidance through the plan is itself moderately modern, its person components are common security strategies. The uniqueness and fruitfulness of CPTED stem from the way in which these strategies are coordinates with, and connected to, the building design process (Gardner, 1981) : 1) Defensible space (Providing maximum control by design characteristics to create defined areas), 2) Territoriality (A sense of place ownership), 3) Surveillance (A high degree of visual control), 4) Lighting (Enhancing natural surveillance and reducing fear), 5) Landscaping (Marking the transition between zones), 6) Physical Security (Making penetration more difficult and time-consuming).

\section{METHODOLOGY}

In order to discover the problem at the Susukino district, an observation was conducted. Then, came up with 'negative space' as the reason why the district is unsafe. Afterward, a deep investigation focussing on land use obtained zoning maps. Each zoning map, later, was compared based on the interview's and survey's results to determine 'the most unsafe district'. Lastly, few recommendations based on CPTED were applied to designs. 


\section{RESULTS AND DISCUSSION}

\section{Negative Space}

Deep inside the most entertaining district in Sapporo, Susukino area showed another face in between buildings and its entertainment facilities. "In most cases, it was reported that most of the non surveillance spaces have high tendencies for negative functions", as stated in the paper entitled "The Enhancement of spaces in between buildings as urban recreation development". This statement along with the author's observation, a negative space in Susukino was identified by three criteria: 1) a long aisle between two buildings which have an extreme proportion between building's height and distance; 2) a space having negative functions; 3) a space with minimum lighting. Those characteristics implied 'not visible space' and indicated 'unsafe space'.

\section{Land Use Identification and Classification ased On Cpted}

Crime Prevention Through Environmental Design is a method of how architectural design prevents criminality. There are six aspects in CPTED (Gardner, 1981): 1) Defensible space, 2) Territoriality, 3) Surveillance, 4) Lighting, 5) Landscaping, 6) Physical Security.

CPTED was applied as the basic to spot and classify the area based on its safety level by observation and interview. There were eleven criteria on observation and interview: 1) function, 2) visitors, 3) working time, (4) robbery, 5) drunkard, 6) police patrol, 7) lighting, 8) accessibility, 9) atmosphere/ situation, 10) transparent elements on façade, 11) proportion of building height and distance. (Figure 1).

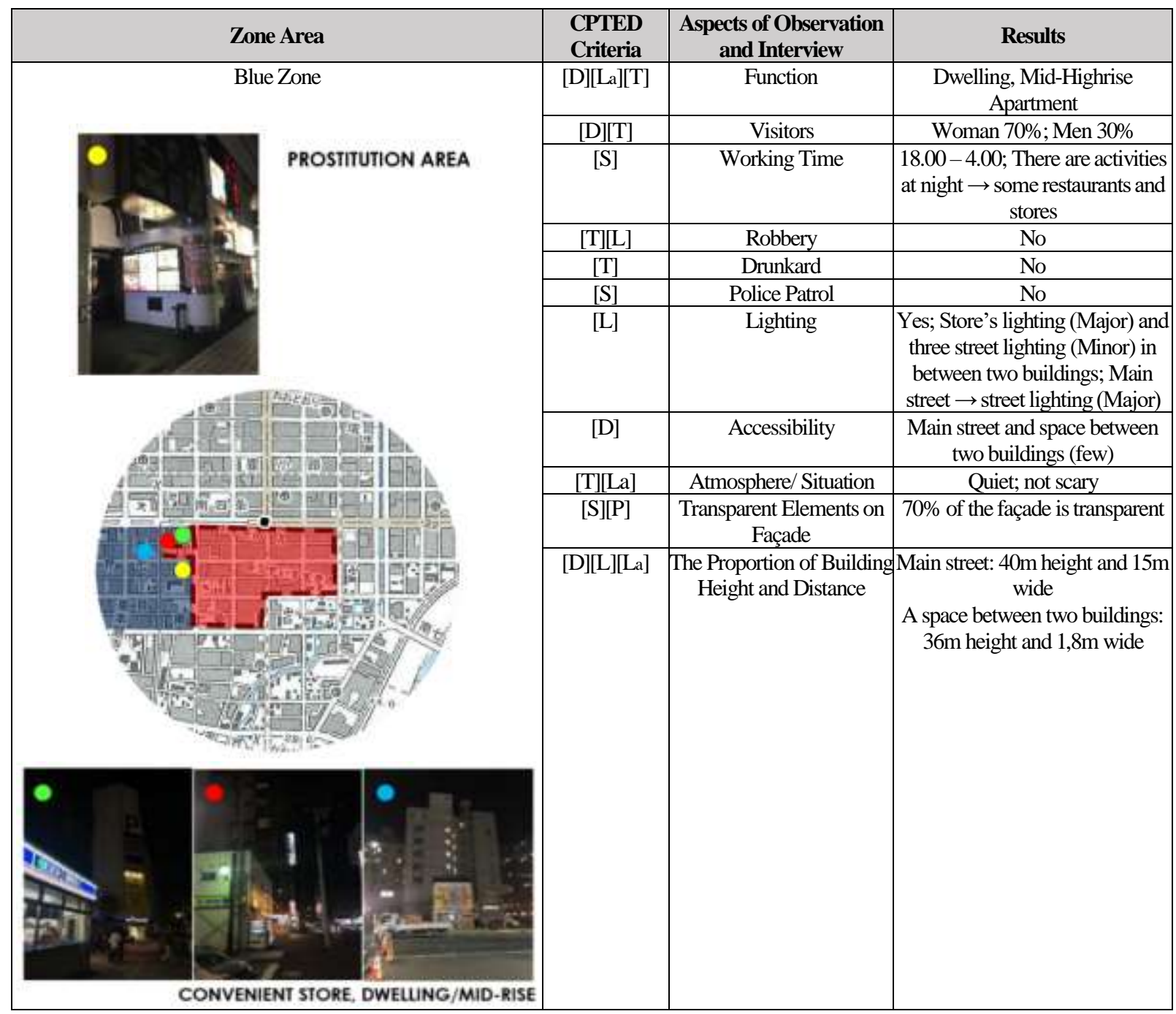




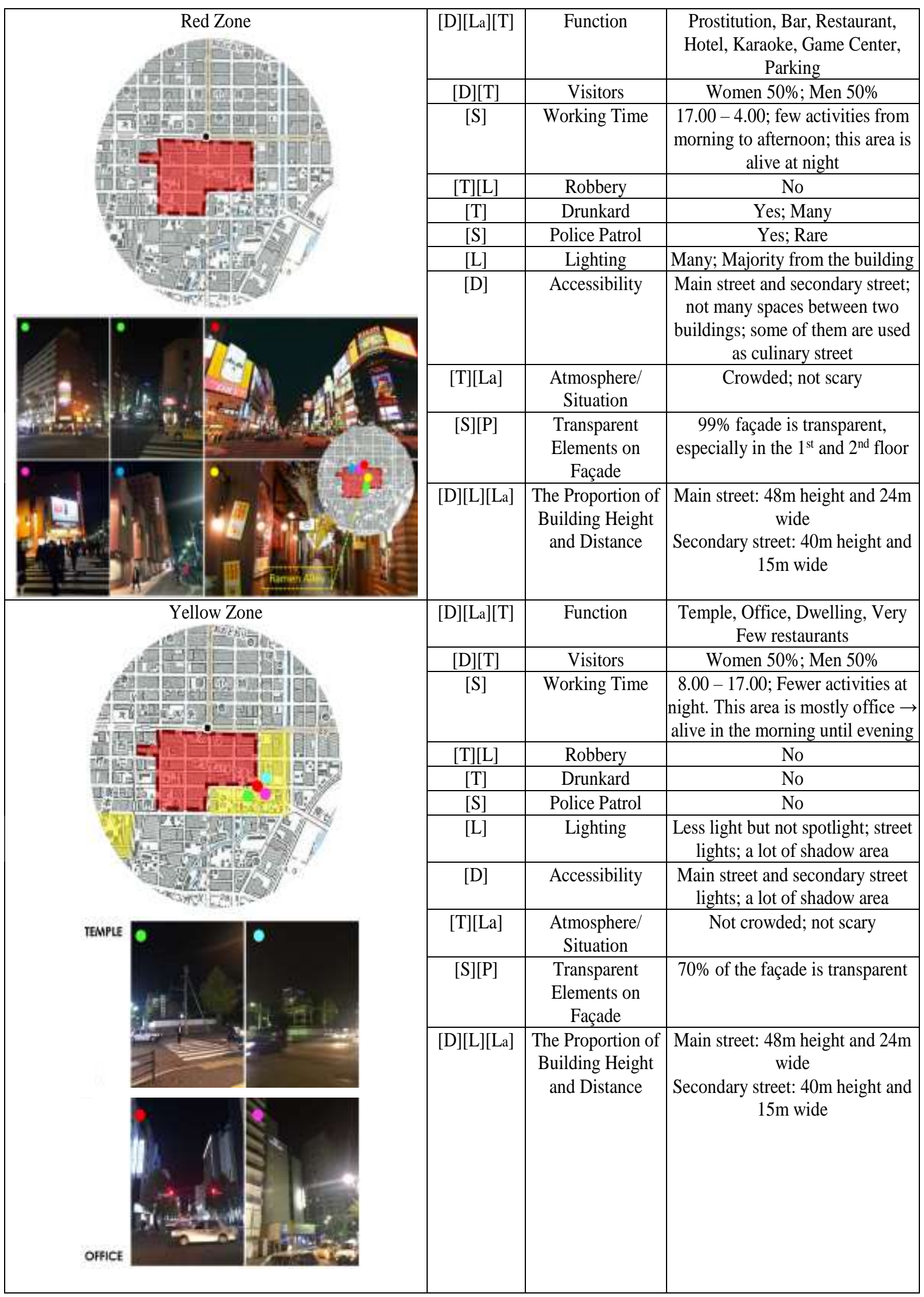




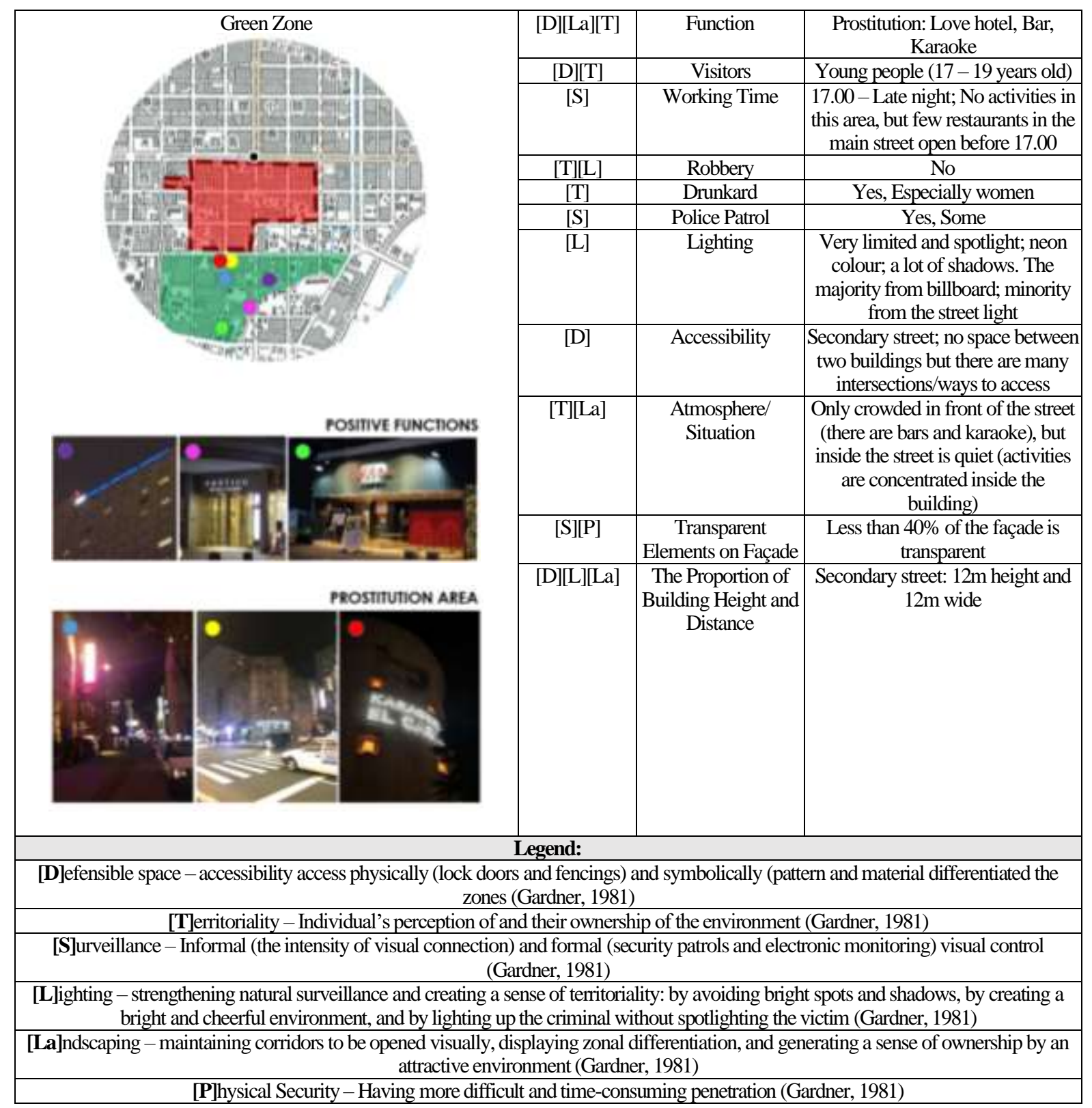

Fig. 1. The existing conditions of the connection street between green and red areas, prepared by the author

There were two solutive designs in order to improve the quality of the street. The first solution was purifying the landmark of the green zone (king XHMU and karaoke EL-CASA) by demolishing the billboards, changing the lighting ambiance from neon colour to vivid colour such as in the red zone, using the building façade as lighting, and creating a light-up pedestrian walkway (Figure 2.). These were important to create a new brand image of the street from a lifeless and dangerous ambiance into a bright and cheerful environment. As stated by Robert A. Gardner, having a pleasing environment would develop a sense of ownership which would increase the territoriality aspect. Moreover, using the façade as lighting would change the domination of bright spots and shadows to be diffuse lighting.

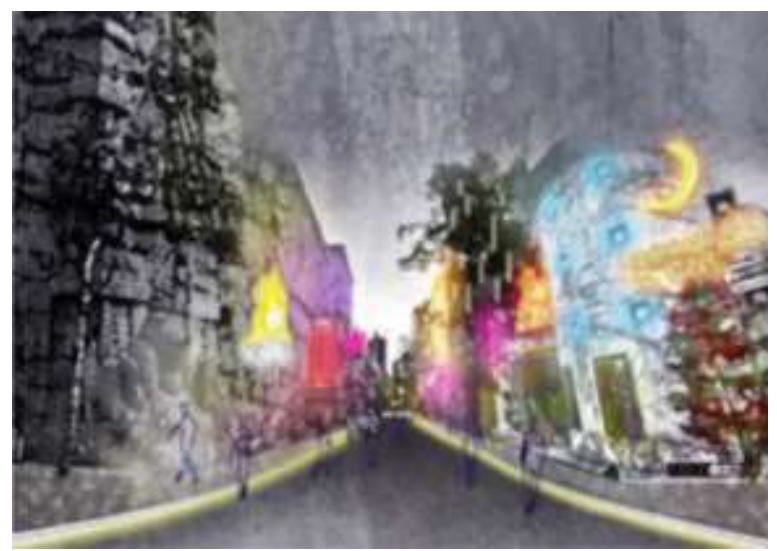

Fig. 2. A perspective of the main face of the green zone, prepared by the author 
The second solution was triggered by the new finding along the street. There was a gap between the existing functions (bars, love hotels, discotheques) and the music hall (ZEPP). The idea was to activate the street by adding positive functions related to young people $(17+$ years old) because the visitors were mostly in that range. Restaurants, food stalls, cafés, game centres, reading corners, and the like were the proposed functions (Figure 3.). Besides, the space gap was a parking lot. Then, the idea was to cover the outer line, which is attached to the street, by restaurants, food stalls, and the like (Figure 4.). This method would be able to remain both functions: parking lot and added functions.

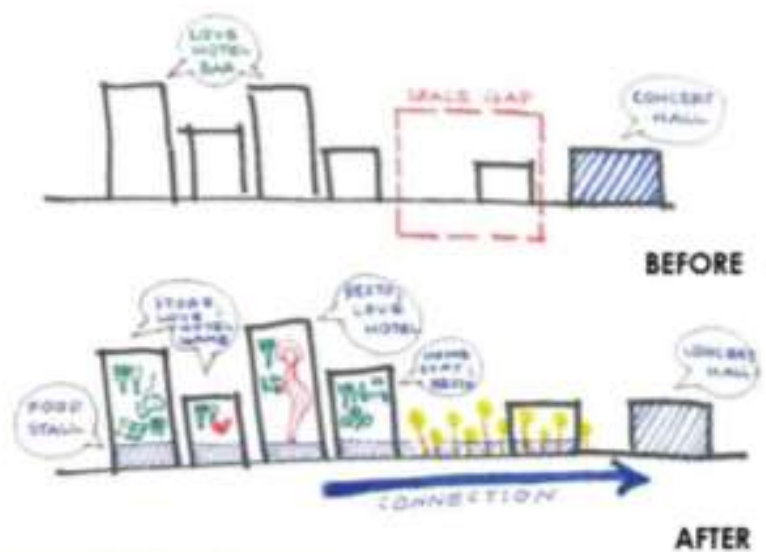

Fig. 3. An illustration of a connection passing through the space gap, prepared by the author
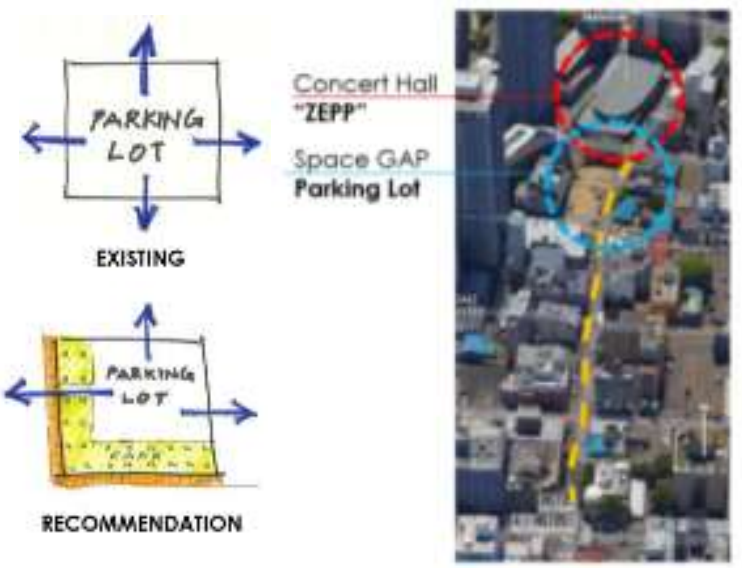

Fig. 4. An illustration of how to add the positive facilities into the space gap, prepared by the author

Moreover, the proposal also concerned on the surveillance and ownership development. As shown in figure 5 , the first-floor areas were open visually by a $90 \%$ transparent façade. This made the street ambiance livelier and increasing visual connections. The addition of street lightings was expected to boost the lively nuance.

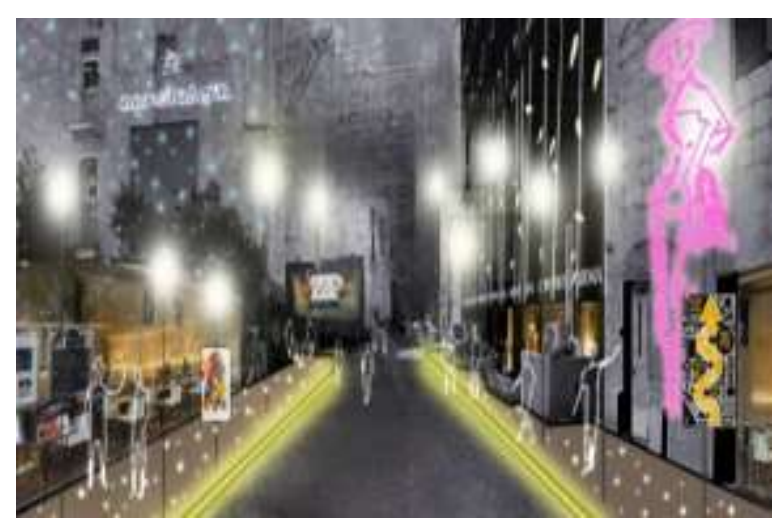

Fig. 5. A perspective of a connection space near the space gap, prepared by the author

\section{CONCLUSION}

As the most unsafe area in Susukino district, redesigning a negative space there by penetrating the red zone to the green zone must pay attention to six existing conditions: billboard, street landmark, pedestrian walkway, street length, function and facilities, and lighting, which represented defensible space, territoriality, surveillance, lighting, landscaping, and physical security in CPTED theory. Later, those six existing conditions triggered the author to come up with seven solutions to bring a safer and livelier ambiance to the green zone: 1) demolishing the billboards, 2) changing the lighting ambiance from neon colour to vivid colour such as in the red zone, 3 ) using the building façade as lighting, 4) creating a light-up pedestrian walkway, 5) using the façade as lighting, 5) activating the street by adding positive functions related to young people, 6) covering all firstfloor areas by $90 \%$ transparent façade, and 7) adding street lighting.

\section{REFERENCES}

Bloomberg. (2013). Sapporo Sex Shops Count: BOJ poll. Business.

Gardner, R. A. (1981). Crime Prevention Through Environmental Design. Retrieved May 28, 2018

Lim, T. F. (2003). Crime Prevention Through Environment Design Guidebook. Singapore: National Crime Prevention Council.

Merry, S. E. (1981). DEFENSIBLE SPACE UNDEFENDED: Social Factors in Crime Control Through Environmental Design. Sage Publication.

Newman, O. (2007). Architectural design for crime prevention. Michigan: National Institute of Law Enforcement and Criminal Justice. 
Peters, L. (2014). Color Science Reveals Which Shades Are Perceived As Sexy, Sad, Calm, and Confident. Retrieved from Bustle: https://www. bustle.com/articles/22110-color-science-revealswhich-shades-are-perceived-as-sexy-sad-calmand-confident.
Samadi, Z. H. (2008). The Enhancement of Spaces in Between Buildings Asurban Recreation Development. ECER Regional Conference 2008, 113. Kelantan. Retrieved from https://www.academia.edu/. 